\title{
The Use of Cone Beam Computed Tomography in Orthodontics: A Review
}

\author{
Huang Anderson T and Huang D* \\ Department of Orthodontics, New York University College of Dentistry, USA
}

Submission: December 10, 2017 ; Published: April 13, 2018

*Corresponding author: Darren Huang, Department of Orthodontics, New York University College of Dentistry, New York, USA, Email: dhuang91@gmail.com

\section{Introduction}

Cone-Beam Computed Tomography (СBCT) was introduced to dentistry in 1998 and has rapidly become a vital resource for precise diagnosis and treatment planning [1]. The orthodontic specialty has been especially attracted to 3-D imaging for a number of applications, most commonly for the localization of impacted or supernumerary teeth and the diagnosis of skeletal deformities [2]. The last ten years have seen an expansion in the scope of CBCT utilization in clinical practice. Research has shown that CBCT imaging can potentially alter treatment decisions in specific clinical scenarios. Recent studies have demonstrated that CBCT is able to more accurately quantify the extent of root resorption in both deciduous canines and maxillary incisors when compared to conventional two-dimensional imaging [3,4].

Despite the reported benefits of CBCT imaging for orthodontic treatment, a consensus on its clinical indications still remains elusive [5]. In 2010, the New York Times reported dentists were excessively using CBCT imaging and placing both children and adolescents at unnecessary risk [6]. The contentious report prompted dental organizations to produce more clearly defined guidelines for the minimization of risk. The 2013 statement from the American Academy of Oral and Maxillofacial Radiology (AAOMR) represents one of the most current and comprehensive set of recommendations for practical CBCT use in the orthodontic patient [7]. Nevertheless, there remains much debate on what constitutes a justifiable application of CBCT primarily because of lack of evidence regarding treatment outcomes in the orthodontic literature [5]. In the following paper, we discuss several indications for CBCT imaging and sound practice based on the current literature and clinical experience.

\section{Clinical Indications}

\section{Localization of impacted teeth}

Studies have shown that CBCT is more sensitive than 2-D radiography for both canine localization, in regards to angulation and crown width, and quantification of root resorption in adjacent teeth [8]. We are in agreement with the AAOMR's 2013 and the European Sedentex CT Project guidelines that suggest in the case of localization of impacted teeth and assessment of related root resorption, 3-D imaging should only be used if the clinical question cannot be answered by more conventional and lower dose radiographs [7]. We have observed that CBCT imaging is particularly useful in cases when substantial overlap occurs between the impacted tooth and the adjacent tooth roots. We recommend CBCT in impaction cases where the canine root is either severely mesio- or disto-angulated, where there is evidence of root resorption in the adjacent teeth, or otherwise when the clinician believes there is insufficient information for diagnosis and treatment planning.

\section{Surgical planning and potential for ankylosis}
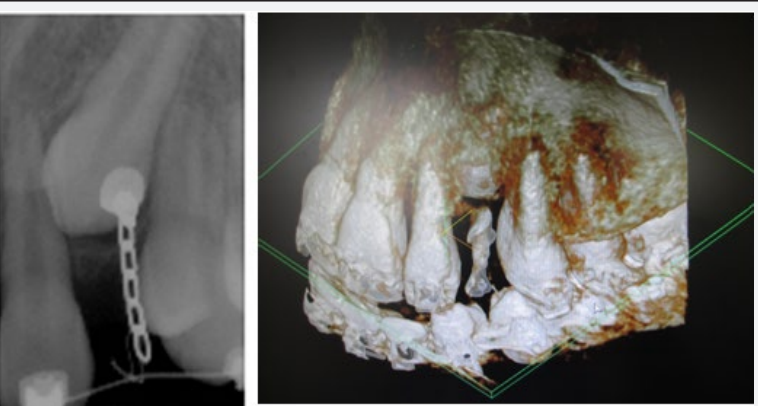

Figure 1: The impacted canine responded with limited movement to orthodontic traction. To assess for ankylosis, we obtained a 3-D image, which showed that the attachment had been dislodged from the crown of the tooth. The 2-D image shows no distinct signs of dislodgement. In this case, 3-D imaging markedly improved the accuracy of diagnosis and treatment decision 
Due to the thinness of the PDL, a high resolution is required for its precise visualization [9]. As demonstrated in Figure 1, we have successfully employed the CBCT to rule out ankylosis in cases where orthodontic traction on impacted teeth produces limited movement. However, the literature has been sparse regarding the use of CBCT imaging for the diagnosis of ankylosis and specific guidelines have not been described.

\section{Diagnosis of skeletal deformities and TMJ disorders}

In cases of severe skeletal deformity, we have often used 3-D imaging for the assessment of facial asymmetry. Both the AAOMR and the European Sedentex CT Project guidelines recognize the CBCT's utility in cases where severe skeletal deformity may require orthognathic surgery, the diagnosis of osseous changes in the TMJ, and the analysis and virtual treatment planning in patients with craniofacial anomalies.

\section{Assessment of alveolar boundary conditions}

Orthodontic movement is often accompanied by alterations in bone morphology and width. For instance, routine orthodontic procedures such as maxillary expansion involves buccal crown tipping of the posterior teeth in addition to a decrease in buccal bone thickness and buccal marginal bone levels [10]. Movements such as the retraction of maxillary incisors in bimaxillary protrusion cases following four 1st premolar extractions or proclination of mandibular incisors in Class II compensatory treatment can result in dehiscences, compromised cortical plate thickness, and secondarily, gingival recession. We have prescribed CBCT imaging in patients where we anticipated large movements of teeth beyond pre-treatment alveolar boundaries, i.e. maxillary expansion in adult patients. The current literature suggests that 3-D imaging is indicated when alveolar boundary conditions have been potentially compromised, whether in cases of reduced buccal/lingual bone width, bimaxillary protrusion, periodontal disease, or alveolar clefting [11].

\section{Assessment of airway morphology and obstructive sleep apnea}

There have a number of studies demonstrating the use of CBCT imaging for the measurement of airway dimensions, particularly in cases of obstructive sleep apnea or subsequent to orthognathic surgery [12]. Research has shown variable reliability in measurement of oropharynx volume and a lack of standardization in regards to methodology. At present, there is no sound justification for CBCT use in airway imaging [13].

\section{Conclusion}

3-D imaging has become increasingly accepted for optimized care in the modern orthodontic practice. Nevertheless, its use should never be considered routine and must be based on individual patient need. Clinical indications, such as localization of impacted teeth, potential for ankylosis, diagnosis of severe skeletal deformities, or the analysis of alveolar boundary conditions, must be assessed in terms of the benefits of improved diagnosis and the risks of increased ionizing radiation for the patient. Essentially, CBCT use should only be employed when there exists the potential for a modification of diagnosis or treatment plan from that obtained using 2-D conventional radiography.

\section{References}

1. Mozzo P, Procacci C, Tacconi A, Martini PT, Andreis IA (1998) A new volumetric CT machine for dental imaging based on the cone-beam technique: preliminary results. Eur Radiol 8(9): 1558-1564.

2. Kapila SD, Nervina JM (2015) CBCT in orthodontics: assessment of treatment outcomes and indications for its use. Dentomaxillofacial Radiology 44(1): 20140282.

3. Kula III TJ, Ghoneima A, Eckert G, Parks ET, Utreja A, Kula K (2017) Two-dimensional vs 3-dimensional comparison of alveolar bone over maxillary incisors with A-point as reference. Am J Orthod Dentofacial Orthop 152 (6): 836.e2-887,e2.

4. Alamadi E, Alhazmi H, Hansen K, Lundgren T, Naoumova JA (2017) comparative study of cone beam computed tomography and conventional radiography in diagnosing the extent of root resorptions. Prog Orthod 18(1): 37.

5. Garib DG, Calil LR. Leal CR, Janson G (2014) Is there a consensus for CBCT use in Orthodontics? Dental Press J Orthod 19(5): 136-149.

6. Bogdanich W, McGinty JC (2010) Radiation worries for children in dentists' chairs. The New York Times.

7. American Academy of Oral and Maxillofacial Radiology (2013) Clinical recommendations regarding use of cone beam computed tomography in orthodontics. [corrected]. Position statement by the American Academy of Oral and Maxillofacial Radiology. Oral Surg Oral Med Oral Pathol Oral Radiol 116(2): 238-257.

8. Algerban A, Jacobs R, Fieuws S, Willems G (2011) Comparison of two cone beam computed tomorgraphic systems versus panoramic imaging for localization of impacted maxillary canines and detection of root resorption. Eur J Ortho 33(1): 93-102.

9. (2012) European Commission. Cone Beam CT for dental and maxillofacial radiology: evidence-based guidelines. SEDENTEXCT Luxembourg.

10. Rungcharassaeng K, Caruso JM, Kan JY, Kim J, Taylor G (2007) Factors affecting buccal bone changes of maxillary posterior teeth after rapid maxillary expansion. Am J Orthod Dentofacial Orthop 132(4): 428.e1428.e8.

11. Leung CC, Palomo L, Griffith R, Hans MG (2010) Accuracy and reliability of cone-beam computed tomography for measuring alveolar bone height and detecting bony dehiscences and fenestrations. Am J Orthod Dentofac Orthop 137(4 Suppl): S109-S119.

12. Weissheimer A, Menezes LM, Sameshima GT, Enciso R, Pham J, et al. (2012) Imaging software accuracy for 3-dimensional analysis of the upper airway. Am J Orthod Dentofacial Orthop 142(6): 801-813.

13. Alsufyani N, Flores-Mir C, Major P (2012) Three-dimensional segmentation of the upper airway using cone beam CT: a systematic review. Dentomaxillofacial Radiology 41(4): 276-284. 
(C) This work is licensed under Creative
Your next submission with Juniper Publishers will reach you the below assets

- Quality Editorial service

- Swift Peer Review

- Reprints availability

- E-prints Service

- Manuscript Podcast for convenient understanding

- Global attainment for your research

- Manuscript accessibility in different formats

( Pdf, E-pub, Full Text, Audio)

- Unceasing customer service

Track the below URL for one-step submission https://juniperpublishers.com/online-submission.php 